Geopolítica(s) Revista de estudios sobre espacio y poder ISSN: 2172-3958

https://dx.doi.org/10.5209/geop.69923

\title{
A construção da RILA entre Argentina, Brasil, Chile e Paraguai e os novos usos territoriais no município de Porto Murtinho, no Brasil
}

\author{
Jackson Batista Bitencourt ${ }^{1}$ \\ Recibido: 2 de junio de 2020 / Aceptado: 28 de mayo de 2021
}

Resumo. Nas últimas décadas, os países sul-americanos forjaram uma agenda de integração que proporcionou uma nova visão estratégica sub-regional, com base em redes estratégicas de infraestrutura. Embora essa agenda tenha sido descontinuada, a construção da RILA (Rota de Integração Latino-Americana), que conectará o centro-sul do Brasil, o Paraguai, o norte da Argentina e o norte do Chile, tem sido um importante elo político sub-regional. Ao interligar regiões economicamente dinâmicas aos portos chilenos, a RILA não somente dinamizará o escoamento da produção regional para mercados asiáticos e americanos, mas, também, estimulará os fluxos comerciais, de investimentos e de pessoas no âmbito sub-regional. Essa rota, contudo, passará, também, regiões menos dinâmicas, como a Faixa de Fronteira do Brasil. Desse modo, identificam-se transformações socioeconômicas derivadas da implantação da RILA em diferentes escalas. Os recursos da análise de escalas de poder e de gestão proporcionam tanto identificar essas transformações quanto relacioná-las a diferentes agentes e atores. No caso do município de Porto Murtinho, no estado do Mato Grosso do Sul, localizado na Faixa de Fronteira do Brasil, a sobreposição de interesses de diferentes agentes e atores tem imposto novos usos ao território. No entanto, há escassa participação da escala local nessas novas dinâmicas territoriais.

Palavras-chave: América do Sul; integração regional; redes de infraestrutura; comércio; território.

\section{[es] La construcción de la RILA entre Argentina, Brasil, Chile y Paraguay y los nuevos usos territoriales en el municipio de Porto Murtinho en Brasil}

Resumen. En las últimas décadas, los países de América del Sur han forjado una agenda de integración que ha proporcionado una nueva visión estratégica subregional, basada en redes estratégica de infraestructura. Si bien esta agenda no ha tenido una implementación continua, la construcción de la RILA (Ruta de la Integración Latinoamericana), que conectará el centro-sur de Brasil, Paraguay, el norte de Argentina y el norte de Chile, ha sido un importante vínculo político subregional. Al vincular regiones económicamente dinámicas con los puertos chilenos, la RILA no solo agilizará el flujo de la producción regional a los mercados asiáticos y estadounidenses, sino que también estimulará el comercio, la inversión y los flujos de personas a nivel subregional. Esta ruta, sin embargo, también pasará por regiones menos dinámicas, como la Franja Fronteriza de Brasil. De esta forma, se identifican las transformaciones socioeconómicas derivadas de la implementación de la RILA a diferentes escalas. Recurrir al análisis de escalas de poder y gestión permiten tanto identificar estas transformaciones como relacionarlas con diferentes agentes y actores. En el caso del municipio de Porto Murtinho, en el estado de Mato Grosso do Sul, ubicado en la Franja Fronteriza brasileña, la superposición de intereses de diferentes

1 Programa de Pós-Graduação em Geografia da Universidade de Brasília (Brasil).

Email: jackbitencourt@yahoo.com.br

https://orcid.org/0000-0003-1399-4879 
agentes y actores ha impuesto nuevos usos al territorio. Sin embargo, hay poca participación de la escala local en estas nuevas dinámicas territoriales.

Palabras clave: América del Sur; integración regional; redes de infraestructura; comercio; territorio.

\title{
[en] The Construction of the RILA between Argentina, Brazil, Chile and Paraguay and the New Land Uses in the Municipality of Porto Murtinho, Brazil
}

\begin{abstract}
In the last decades, South American countries have forged an integration agenda that has provided a new sub-regional strategic vision, based on strategic infrastructure networks. Although this agenda has not shown a continuous implementation, the construction of the RILA (Latin American Integration Route), which will connect south-central Brazil, Paraguay, northern Argentina and northern Chile, has been an important subregional political link. Through linking the dynamic economic regions with Chilean ports, RILA will not only boost the flow of regional production to Asian and American markets, but will also stimulate trading, investment and people flows at the sub-regional level. However, this route will also cross through less dynamic regions, such as the Brazilian Border Strip. Thereby the socioeconomic transformations derived from the implementation of RILA at different scales are identified. Using the scales analysis of power and management allow both to identify these transformations and to relate them to different agents and actors. In the case of the municipality of Porto Murtinho, in the state of Mato Grosso do Sul, located in the Brazilian Border Strip, the overlapping of interests from different agents and actors has imposed new uses on the territory. However, there is a little participation of the local scale in these new territorial dynamics.
\end{abstract}

Keywords: South America; regional integration; infrastructure networks; trade; territory.

Sumario. Introdução. 1. O desenvolvimento de redes de infraestruturas na América do Sul. 2. A relevância geoestratégica do Eixo Interoceânico Central (IOC). 3. Desdobramentos da RILA no estado do Mato Grosso do Sul - Brasil. 4. Novos usos territoriais em Porto Murtinho, MS, Brasil. Considerações Finais. Agradecimentos. Referências bibliográficas.

Cómo citar: Bitencourt, J. B. (2021). A construção da RILA entre Argentina, Brasil, Chile e Paraguai e os novos usos territoriais no município de Porto Murtinho, no Brasil. Geopolítica(s). Revista de estudios sobre espacio y poder, 12(2), 207-229. https://dx.doi.org/10.5209/geop.69923

\section{Introdução}

A região de fronteira apresenta uma multidimensionalidade de processos políticos e econômicos que derivam, por vezes, de sobreposições de projetos, realizações e iniciativas estatais e privadas ao longo do tempo. Embora o conceito de fronteira esteja relacionado à projeção de soberania do Estado "para fora", simbolizado, por exemplo, pelos marcos de fronteiras, em um contexto de busca de integração, com a finalidade de incrementar a participação no comércio global, os países sul-americanos têm buscado uma convergência política para dinamizar projetos que facilitem o escoamento da produção regional por meio de áreas fronteiriças.

Nesse contexto, a integração de redes de infraestruturas ganhou centralidade política em países sul-americanos, nas últimas décadas. Projetos binacionais de integração, que remontam às primeiras décadas do século XX, passam pelo planejamento e pela implementação de infraestruturas internacionais. Em alguns casos, tais projetos foram desarticulados devido a inflexões políticas e econômicas nos 
governos nacionais. De todo modo, eles estimularam a emergência de uma nova visão estratégica sobre o ordenamento territorial sul-americano (Wegner, 2018).

O projeto da RILA (Rota de Integração Latino Americana), que está em fase adiantada de construção, conectará o centro-sul do Brasil ao litoral norte do Chile, por meio de redes rodoviárias que passarão pelo território do Paraguai e do norte da Argentina. No território do Brasil, destaca-se a conexão do estado do Mato Grosso do Sul (MS) e, principalmente, do município fronteiriço de Porto Murtinho, como regiões que serão beneficiadas por esse projeto, uma vez que estão em contato com países vizinhos.

O projeto inicial de uma conexão rodoviária bioceânica no centro-sul do subcontinente entre o deriva da agenda de integração que foi desenvolvida após a I Reunião de Presidentes da América do Sul, de setembro de 2000, realizada na cidade de Brasília, capital do Brasil. Com base nessa agenda, foi lançada a IIRSA (Iniciativa para a Integração da Infraestrutura Regional Sul-Americana), que não somente desnudou a situação precária das redes de infraestruturas subcontinentais mas, também, a necessidade de reestruturá-las e integrá-las. O objetivo principal passou a ser o fomento à integração estratégica, comercial e produtiva e, por conseguinte, o desenvolvimento dos países formadores desse subcontinente.

Embora os projetos da RILA não sejam financiados exclusivamente por instituições estatais, a consecução e o planejamento deles apresenta a participação central de agências governamentais. A existência de diversas fontes de financiamentos corrobora o conceito de poder de Parsons, enquanto concentração que "assegura o cumprimento de obrigações impostas por unidades num sistema de organização coletiva" (Faria, 2003, p.102). Desse modo, agentes estatais e atores públicos e privados têm buscado, conjuntamente, prover redes de infraestrutura que possibilitem a integração regional, na medida em que estimulem o desenvolvimento por meio do escoamento da produção e da redução de custos operacionais e logísticos.

Destarte, a construção da RILA apresenta diferentes correlações entre agentes e atores políticos. Conforme se altera o nível de análise, mormente a escala geográfica, verifica-se relações distintas entre agentes e atores, processos, complexidades e resultados esperados. Assim, a despeito de incertezas em relação ao futuro da UNASUL (União de Nações Sul-Americanas), responsável pela carteira de projetos da IIRSA, por meio do COSIPLAN (Conselho Sul-Americano de Infraestrutura e Planejamento), a execução desse projeto representa um rearranjo de relações de poder na escala sul-americana, assim como na regional e na local. Isso ocorre porque, na escala regional e, principalmente, na local, há a imposição de novos usos ao território, a fim de dinamizar a competitividade de segmentos produtivos domésticos em mercados americanos e asiáticos. Além disso, representa a existência de uma racionalidade geopolítica que se sobrepõe, parcialmente, às significativas inflexões que se sucederam no contexto político brasileiro, ao longo das últimas décadas.

Assim, o processo de construção da RILA desencadeia inflexões econômicas e geoestratégicas na Faixa de Fronteira do Brasil com o Paraguai, notadamente, no município de Porto Murtinho (MS). Com base nessa hipótese, o presente artigo apresenta o objetivo principal de elencar as vantagens geoeconômicas que serão proporcionadas pela RILA a segmentos produtivos da Argentina, do Brasil, do Chile e do Paraguai, uma vez que "uma macrovisão do território brasileiro deve visualizar, também, a unidade maior do subcontinente sul-americano" (Moraes, 2005, p.46). Além disso, como objetivos específicos, busca-se identificar transformações 
econômicas e geoestratégicas derivadas da implantação da RILA que ocorrem, atualmente, na escala regional e local, no Brasil. Por fim, na escala local, visa-se analisar as transformações territoriais que impactam o município fronteiriço de Porto Murtinho, no estado do Mato Grosso do Sul, Brasil.

A fim de atingir esses objetivos, o texto identifica como os objetivos estratégicos de diferentes agentes e atores se manifestam de modo convergente ou divergente, assim como podem desencadear novos usos territoriais ${ }^{2}$. Desse modo, o recurso às escalas geográficas pretende evidenciar "a articulação entre as escalas, por um lado, e, por outro, [...] representar uma esfera global através da localidade ou especificar uma localidade numa representação à escala global" (Gama, 1998, p. 20). Isso possibilita avaliar como a construção da RILA dinamizará novas relações de poder em diferentes escalas. Ademais, o texto enfatiza as possíveis consequências dessas mudanças na relação entre o município de Porto Murtinho/MS e as escalas nacional, supranacional e global.

Ainda com base nas escalas geográficas de poder e gestão, este artigo identifica diferentes atores públicos e privados que atuam na construção da RILA e como se beneficiarão da fluidez logística proporcionada por essa conexão rodoviária. Desse modo, a compreensão acerca dos novos usos territoriais que derivam da implantação da RILA depende não apenas da ação de atores locais, mas, acima de tudo, de atores extra-locais que buscam projetar interesses específicos, a fim de obter ganhos políticos e econômicos por meio do uso dessa conexão logística. Desse modo, este artigo está organizado em subitens que abordam essas relações de poder na escala sul-americana, na escala do recorte territorial bioceânico, na estadual e, por fim, na local.

\section{O desenvolvimento de redes de infraestruturas na América do Sul}

As fronteiras, mesmo aquelas fundadas em limites naturais, como rios e cadeias montanhosas, tendem a apresentar inflexões quanto ao dinamismo político e econômico, de acordo com as conjunturas históricas. Esses dois conceitos, fronteira e limite, por conseguinte, apresentam, geralmente, significados distintos. Enquanto a fronteira tende a apresentar "forças centrífugas", os limites são orientados por "forças centrípetas". Desse modo, a fronteira atrai maior atenção do Estado do que os limites, no que se refere à gestão do território e à segurança. Ademais, a fronteira pode ser um catalizador para a integração internacional, "na medida que for uma zona de interpenetração mútua e de constante manipulação de estruturas sociais, políticas e culturais distintas [...]" (Machado, 1998, p.42).

Sob a égide da UNASUL, os projetos derivados da IIRSA, como a implementação dos EIDs $^{3}$ (Eixos de Desenvolvimento) e dos PSIs (Processos Setoriais de Integração), foram incorporados pelo COSIPLAN, que liderou os estudos relacionados à interconectividade física e energética entre os países da região, até o relativo ocaso

2 O conceito de uso territorial deriva da ideia de território usado, que abrange todos os usos, os interesses e as políticas adotadas para atingir objetivos determinados (Santos, 2000).

3 A implementação de EIDs e PSIs buscou estabelecer um paradigma de planejamento de investimentos em infraestrutura para criar uma visão sistêmica de desenvolvimento. Desse modo, propunha o reordenamento territorial por meio da implantação de redes regionais de transporte, telecomunicações e energia (Batista, 1997). 
político da organização ${ }^{4}$. Com o objetivo de desenvolver uma infraestrutura para integração regional e de fomentar a cooperação regional mediante alianças estratégicas entre membros da UNASUL, o COSIPLAN propôs projetos de infraestrutura logística, energética e comunicacional que buscam, também, estimular a transformação parcial de fronteiras de zonas de tensão em zonas de contato e articulação.

O planejamento territorial do COSIPLAN foi organizado com base no conceito de EIDs ${ }^{5}$. Ao ser provida de infraestrutura logística, energética e comunicacional, é esperado que uma determinada faixa territorial dinamize os fluxos de bens e de serviços, de pessoas e de informações, no âmbito interno e na relação entre essa faixa e diferentes partes do mundo (Cosiplan, 2020). O consenso entre diferentes países sobre a implantação dessas redes de infraestrutura revela a importância da circulação e da comunicação para modelar e produzir o território (Raffestin, 1993, p.204). Isso representa não somente a superação relativa de distâncias físicas entre diferentes nós, mas, também, a importância relativa de determinados fluxos, de acordo com a densidade e a diversidade das redes físicas, econômicas e comunicacionais.

Desse modo, a América do Sul foi subdivida em dez EIDs, com a finalidade de planejar o provimento desses territórios com infraestruturas suficientes para desencadear o desenvolvimento regional, de acordo com potencialidades identificadas em cada um desses recortes territoriais. O EID Interoceânico Central (IOC), que abarca o território que será conectado pela RILA, inclui uma superfície territorial que atinge as duas costas oceânicas sul-americanas, o que representa uma rede logística que une importantes portos marítimos, fluviais e nós logísticos em Argentina, Brasil, Chile e Paraguai. Nesse EID, a rede viária apresenta 1.854.372 quilômetros de rodovias, dos quais, somente $14 \%$ estão atualmente pavimentadas. A rede ferroviária, por sua vez, dispõe de 40.146 quilômetros de extensão, mas não há conexões densas que proporcionem o escoamento de produtos e serviços e a circulação de passageiros entre todos os países abrangidos pelo IOC. O IOC abrange 29 portos principais, a maioria localizada nas costas oceânicas do Atlântico e do Pacífico (Cosiplan, 2017, p.199). Há escassa conexão logística entre esses países limítrofes e, por conseguinte, é necessário implantar redes de infraestruturas internacionais, a fim de impulsionar a cooperação, o desenvolvimento e a integração regional.

A criação do PROSUL não proporcionou avanços em relação à agenda de integração de infraestruturas na América do Sul. Embora tenha sido lançado como uma inciativa flexível para que decisões fossem tomadas de modo célere e desburocratizado, o PROSUL ainda não logrou êxito no que se refere à consecução de projetos sub-regionais de integração de infraestruturas, ainda que entre os seis GTs (Grupo de Trabalho) vinculados ao Foro, um seja dedicado à infraestrutura. Argentina, Brasil, Chile e Paraguai, países que serão interligados pela RILA, iniciaram negociações que culminaram na construção da RILA em 2015, na XLIX Reunião Ordinária do Conselho do Mercado Comum e Cúpula de Chefes dos Estados Partes do

4 Em 22 de março de 2019, ocorreu uma reunião de presidentes sul-americanos na capital chilena, quando se adotou a "Declaração Presidencial sobre a Renovação e o Fortalecimento da Integração da América do Sul". Nesta Declaração, oito países (Argentina, Brasil, Chile, Colômbia, Equador, Guiana, Paraguai e Peru) indicaram a intenção de construir e de consolidar um espaço regional de coordenação e cooperação, o que resultou no lançamento das bases do PROSUL (Foro para o Progresso da América do Sul). Essa iniciativa substitui, para esses países, o papel inicialmente conferido à UNASU (MRE, 2019).

5 Um EID representa uma faixa territorial abrangendo mais de um país e que inclui dotação de recursos naturais, assentamentos humanos, áreas produtivas e serviços logísticos. 
MERCOSUL e Estados Associados, realizada em Assunção, capital do Paraguai, a Declaração de Assunção sobre Corredores Bioceânicos, em 21 de dezembro de 2015 (MRE, 2015). Por meio do estabelecimento de $\mathrm{GTs}^{6}$, representantes dos países envolvidos passaram a debater a construção de uma conexão rodoviária que proporcionasse maior integração regional, facilitação do trânsito transfronteiriço e autonomia política. Ademais, a fim de dinamizar a conclusão desse projeto logístico, cada país comprometer-se-ia a realizar as obras em seu próprio território.

Essa primazia da realização de planejamento e de execução de obras com base em decisões nacionais converge com opções de governos mais afeitos à defesa da soberania que, nos últimos anos, têm predominado na América do Sul. Assim, a possibilidade de incorporação dos projetos de redes de infraestruturas sul-americanas pela OBOR (One Belt, One Road), que fora suscitada pelo ex-presidente argentino Maurício Macri (Efe, 2017), não mais é contemplada pelos líderes de países da região. No entanto, a hipótese de fragmentação do espaço por meio do "poder infraestrutural " (Herrera, 2019, p.41-68) permanece válida, na medida em que a RILA promova um aumento da dependência econômica sul-americana em relação à China, tanto em relação à demanda de commodities quanto à oferta de bens manufaturados. A redução de custos logístico tende a aumentar a competitividade de commodities na China, ao passo que os produtos de maior valor agregado ampliarão o acesso a mercados sul-americanos, o que causaria retração significativa dos segmentos industriais regionais. Fundamentalmente, uma nova hierarquia espacial e, portanto, novas relações de dependência, surgiriam desse processo (Herrera, 2019). Com base em análises preliminares de Parkinson (2020), a RILA proporcionará ganhos de competitividade, principalmente, para segmentos produtivos de médio e alto valor agregado, além de aprofundar as complementariedade comercial sub-regional, o que afastaria, a princípio, esse processo derivado do "poder infraestrutural".

Os governos de Argentina, Brasil, Chile e Paraguai, portanto, visam à retomada do crescimento econômico por meio, principalmente, do incremento de excedentes exportáveis. Embora o governo argentino de Alberto Fernández seja mais recalcitrante em relação à abertura comercial, os governos de Brasil, Chile e Paraguai buscam atingir ganhos de competitividade como instrumento para aumentar a participação de segmentos produtivos nacionais tanto no comércio internacional quanto nas cadeias globais de valor. Em relação à RILA, os ganhos de competitividade das exportações, principalmente de produtos de maior valor agregado, tendem a ser fundamentais para, em uma conjuntura de pós-pandemia de Covid-19, alavancar o crescimento econômico dos países da região, uma vez que o desencadeamento desse crescimento dependerá, também, da disponibilidade de redes de infraestruturas transfronteiriças resilientes, eficientes e sustentáveis (CEPAL, 2021).

\footnotetext{
De acordo com essa Declaração, cada Ministério de Relações Exteriores deveria criar um GT que integrasse representantes dos Ministérios de Infraestrutura, Obras Públicas e Transportes e instituições vinculadas dos quatro países, a fim de impulsionar os estudos técnicos e formular recomendações à concretização de um corredor viário entre Campo Grande e Porto Murtinho (Brasil); Carmelo Peralta, Mariscal Estigarribia e Pozo Hondo (Paraguai); Misión La Paz, Tartagal, Jujuy e Salta (Argentina); e Sico, Jama, Puertos de Antofagasta, Mejillones e Iquique (Chile) (MRE, 2015).
} 


\section{A relevância geoestratégica do Eixo Interoceânico Central (IOC)}

Situado entre os paralelos $15^{\circ} \mathrm{S}$ e $25^{\circ} \mathrm{S}$, a região que corresponde ao IOC compreende parte das superfícies territoriais da Bolívia, do Brasil, do Chile, do Peru e todo o território do Paraguai ${ }^{7}$. Enquanto na fachada atlântica dessa região há planaltos e serras que apresentam elevações que ultrapassam 1.500 metros, na fachada pacífica há a cordilheira dos Andes, que, na região que compreende o IOC, supera os 6.000 metros. Entre essas duas áreas de altitudes mais elevadas, há o predomínio de planícies e de altitudes relativamente modestas, onde se faz presente a planície do Pantanal, no Brasil, e o Chaco, entre o sul da Bolívia e o Paraguai.

O predomínio de índices pluviométricos que superam os $1.000 \mathrm{~mm}$ anuais, exceto na região central do Chaco, que apresenta índice inferior a $700 \mathrm{~mm}$ anuais, combinado com variações de climas tropicais, que apresentam uma estação sem chuvas, perfaz uma combinação favorável à prática de atividades agropecuárias. Mesmo que, inicialmente, tenham apresentado limitações à prática agrícola, devido à elevada acidez, os solos dessa região, por meio de técnicas de correção, como a calagem, e de recursos informacionais, como a agricultura de precisão, têm proporcionado aumento expressivo da produtividade, notadamente, de soja e de milho (Cosiplan, 2017). Assim, a região Centro-Oeste do Brasil, o leste do Paraguai, o oeste da Bolívia e o nordeste da Argentina têm ampliado a participação regional no comércio mundial tanto de commodities agrícolas quanto de carne bovina.

Na medida em que abrange a faixa centro-sul da América do Sul, entre os oceanos Atlântico e Pacífico, a região do IOC abrange não somente grandes centros industriais, como a Região Metropolitana de São Paulo, mas, também, importantes áreas de produção agropecuária, como a região Centro-Oeste do Brasil e a porção oriental do Paraguai, e de recursos minerais, como o norte do Chile e o centro-leste da Bolívia. Além disso, os expressivos aglomerados urbanos que existem no centro-sul do Brasil, em Assunção, capital do Paraguai e no litoral norte do Chile constituem importantes centros de consumo, o que tem favorecido a intensificação dos fluxos regionais de comércio nas últimas décadas. Consequentemente, o maior adensamento de segmentos produtivos justifica a necessidade de maior disponibilidade de redes logísticas multimodais que proporcionem a circulação tanto de fatores de produção quanto de produtos e serviços destinados ao mercado consumidor.

A articulação entre esses aspectos fisiográficos e produtivos é determinante para o planejamento logístico da região do IOC. Grande parte da produção agropecuária oriunda dessa região é exportada, principalmente, para países que compõe a bacia do Pacífico. Destarte, há três alternativas logísticas para o escoamento dessa produção: o modal hidroviário, por meio da hidrovia Paraná-Paraguai, até os portos argentinos, como o de Santa Fé e o de Buenos Aires; o modal rodoviário, até os portos atlânticos de Santos e de Paranaguá, no Brasil; e o modal rodoviário, até os centros de processamento de soja, na Argentina.

A hidrovia Paraná-Paraguai é a via estratégica para o transporte da produção de grãos e de minérios produzidos nos estados de Mato Grosso e de Mato Grosso do

O IOC abrange aproximadamente $15 \%$ da superfície territorial $(2.881 .860 \mathrm{~km} 2)$ e $25 \%$ da população da América do Sul (107.319.693 habitantes), o que o torna uma dos três EIDs mais densamente povoados do subcontinente, com aproximadamente 37 habitantes $/ \mathrm{km} 2$. Além disso, concentra $30 \%$ do PIB da América do Sul (US\$ 1,348,366.00) (Cosiplan, 2017; Cepalstat, 2021). 
Sul, no Brasil, no leste da Bolívia e no Paraguai. Mesmo que seja considerada economicamente viável (Antaq, 2019), essa hidrovia apresenta significativa sinuosidade, insuficiência de terminais para armazenagem e baixa profundidade, o que limita a navegação de embarcações de médio e de grande porte. Além disso, ao longo da estação sem chuvas, entre os meses de março e setembro, o trecho próximo à montante, que abrange o leste da Bolívia e o estado brasileiro do Mato Grosso tornase impróprio à navegação, devido à baixa profundidade do canal de navegação. Os modais rodoviários até os portos de Santos, Paranaguá e Buenos Aires são, portanto, as principais rotas de escoamento da produção agropecuáriada região do IOC.

A fim de criar uma alternativa logística mais dinâmica e menos onerosa, o COSIPLAN estabeleceu, no âmbito da região do IOC, dois grupos de projetos que fundamentariam conexões físicas no sentido leste-oeste. Um grupo constituiria a conexão entre Brasil, Paraguai, Bolívia e Chile, enquanto o outro formaria outra ligação, entre Brasil, Paraguai, Argentina e Chile. Com base na formação do segundo grupo, as autoridades governamentais dos respectivos países formalizaram, por meio da Declaração de Assunção sobre Corredores Bioceânicos de 2015, o início dos estudos técnicos que embasaram a implantação da RILA (MRE, 2015).

Embora os projetos iniciais de um Corredor Rodoviário Bioceânico abrangessem a Bolívia, o país não foi incluído nas negociações, tampouco nos GTs. Basicamente, três aspectos inviabilizaram a participação boliviana: "1) as tensões geopolíticas em elevação com o Chile; 2) as características das rodovias da Bolívia; e, 3) a legislação boliviana que permite vender combustiveis com valores majorados para motoristas que conduzam veículos com placas de outro país" (João Carlos Parkinson) ${ }^{8}$.

Em 2015, quando as negociações intergovernamentais para a construção de um Corredor Rodoviário Bioceânico iniciaram, La Paz mantinha um caso contra Santiago na Corte Internacional de Justiça (CIJ), a fim de forçar as autoridades chilenas a negociar com os bolivianos uma saída soberana para o oceano Pacífico ${ }^{9}$. Até 2018, quanto a CIJ proferiu a sentença, houve diversas hostilidades diplomáticas entre os países, o que inviabilizou a incorporação da Bolívia à RILA. Além disso, embora apresentam boa qualidade, as rodovias que cruzam o território boliviano não dispõem de pontos de serviços, como postos de combustíveis, oficinas e restaurantes, fora de áreas urbanas. Desse modo, o tráfego de longas distâncias de caminhões de cargas torna-se inviável, uma vez as há centros urbanos bolivianos que apresentam mais de 300 quilômetros de distância entre si. Por fim, a legislação boliviana vigente prevê que os motoristas de veículos com placas estrangeiras paguem preços distintos para reabastecer os veículos: o custo do combustível, nesses casos, é, em média, o dobro do valor pago por cidadãos bolivianos. Muitos postos de combustíveis bolivianos também proíbem o abastecimento de veículos com placas de países vizinhos. A despeito desses aspectos deletérios, "autoridades de Argentina, Brasil, Chile e

\footnotetext{
Dados de entrevista realizada com o diplomata brasileiro João Carlos Parkinson, que tem representado o Brasil nas negociações internacionais relacionadas à RILA. Entrevista realiza em 18 de março de 2021.

9 A Guerra do Pacífico ocorreu entre 1879 e 1883, quando as forças conjuntas de Bolívia e Peru enfrentaram as do Chile. A vitória chilena foi formalizada por meio do tratado de Paz e Amizade de 1904, entre Bolívia e Chile, que tornou absoluta e perpétua a cessão de territórios bolivianos que correspondiam ao Departamento do Litoral, o que transformou a Bolívia em um país mediterrâneo. Em 2013, a Bolívia apresentou perante a Corte Internacional de Justiça de Haia (CIJ) um requerimento contra o Chile, a fim de forçar o país vizinho a negociar uma saída para o mar. Em outubro de 2018, a CIJ concluiu que as notas, atas e diferentes declarações entre ambos os países ao longo do século XX e no início do XXI comprovam que existiu uma intenção de negociar por parte do Chile, o que frustrou os objetivos das autoridades bolivianas (Bitencourt, 2021).
} 
Paraguai têm debatido a possibilidade de conectar a Bolivia à RILA, possivelmente, por meio de do norte do território argentino" (João Carlos Parkinson).

Os atuais projetos logísticos relacionados à RILA apresentaram funções geoestratégicas fundamentais à integração sul-americana, que se assemelham àquelas identificadas inicialmente pelo COSIPLAN. Entre essas funções, destaca-se

a de reduzir os custos logísticos de cargas oriundas do norte da Argentina, do sul da Bolívia, do norte do Chile, do centro-sul do Brasil e do Paraguai, que são embarcadas em portos na costa do Atlântico e na do Pacífico; de estimular a complementariedade produtiva entre esses países vizinhos; de apoiar o setor de turismo na região do Pantanal; de reduzir os custos alfandegários entre os países vizinhos (Cosiplan, 2017, p.209).

A configuração geográfica do subcontinente América do Sul favorece a construção de conexões entre as duas costas oceânicas que banham a região do IOC. Além da presença de importantes concentrações urbanas, industriais e de produção agropecuária e mineral, a distância entre o litoral brasileiro e o chileno é de aproximadamente $3.000 \mathrm{~km}$. Na medida em que se avança para o norte, essa distância entre as duas costas marítimas eleva-se gradualmente, devido ao alargamento da faixa continental. Assim, a existência de estruturas portuárias que disponham de infraestruturas suficientes para embarque célere e menos oneroso é estratégica, principalmente, quanto há intenso movimento de cargas em direção aos portos, visto que as exportações de commodities agrícolas se concentram durante o período de safra.

Em suma, a existência de grandes centros urbanos e de importantes segmentos produtivos na região do IOC reforça a busca de integração de infraestruturas logísticas regionais. Embora Argentina, Brasil, Chile e Paraguai disponham de boas conexões domésticas, que conectam os segmentos produtores e consumidores domésticos, as conexões logísticas internacionais são escassas. Além de adensar os fluxos regionais de cargas, a construção da RILA proporcionará, também, um padrão mais efetivo de integração regional, visto que será uma rota rodoviária mais eficiente para o transporte de cargas do que aquelas disponíveis atualmente. Nesse contexto, de acordo com Parkinson (2020), a construção de terminais multimodais e de processamento de cargas, no município de Porto Murtinho e no de Campo Grande, ambos no estado do Mato Grosso do Sul, resultará em redução de custos de frete de bens e de insumos importados, principalmente, para a região de influência dessa rota. Por fim, a facilitação da mobilidade estimulará os fluxos de turismo, o que tende a beneficiar áreas que apresentam atrações naturais, como o Pantanal brasileiro e o deserto do Atacama.

\section{Desdobramentos da RILA no estado do Mato Grosso do Sul - Brasil}

A fluidez decorrente da construção de infraestruturas de transportes proporciona ganhos econômicos, sociais e estratégicos que tendem a transformar uma rodovia em um corredor de desenvolvimento. O estímulo a novos fluxos de comércio e de investimento, além da criação de empregos, intensifica a coordenação entre agentes e atores nas escalas internacional, nacional e local. 
A construção da RILA busca não somente desencadear o desenvolvimento regional, mas, também, estimular a coordenação entre os diferentes agentes e atores políticos e econômicos que mantém relações econômicas e políticas com a região de influência desse corredor internacional. Desse modo, a opção pela integração rodoviária busca mitigar a escassez de integração logística que tem, historicamente, preponderado entre o Brasil e os países próximos: Argentina, Chile e Paraguai. Embora estejam fisicamente próximos, a maior parte do comércio realizado entre o Brasil e esses países dá-se por meio de vias marítimas. O fato de amalgamar interesses de grupos políticos e produtivos que integram diferentes escalas geográficas de poder, tanto no âmbito nacional quanto no internacional, reforça a iniciativa de estabelecer maior convergência entre os interesses distintos de cada integrante, o que favorece a atração de investimentos públicos e privados para a área de influência da RILA e a mitigação de assimetrias socioeconômicas que tornam a Faixa de Fronteira ${ }^{10}$ do Brasil uma área periférica em relação àquelas consideradas economicamente mais dinâmicas.

Com aproximadamente 3.503 quilômetros de extensão, a RILA será uma alternativa logística eficiente para segmentos produtivos e turísticos do centro-sul do Brasil, do Paraguai, do sul da Bolívia, do norte da Argentina e do norte do Chile. De acordo com a Tabela 1, percebe-se que a pavimentação dos trechos dessa rota, que compete a cada um dos países em seus respectivos territórios, está em fase final de conclusão. O governo do Paraguai obteve financiamento do FONPLATA (Fundo Financeiro para Desenvolvimento da Bacia do Prata) para pavimentar o trecho de 318 quilômetros da Transchaco entre Loma Plata e Pozo Hondo, o que permitirá a conclusão das obras da RILA no país guarani (MOPC, 2020). Ademais, o trecho de 20 quilômetros no território da Argentina, entre Pozo Hondo e Tartagal será pavimentado em 2021, uma vez que a conclusão da RILA é uma prioridade para o governo argentino, segundo declaração do presidente Alberto Fernandez (Página 12, 2021).

Tabela 1. RILA: trecho rodoviário em cada país (em quilômetros)

\begin{tabular}{|l|c|c|}
\hline \multicolumn{1}{|c|}{ País } & Total $(\mathrm{km})$ & Pavimentado $(\mathrm{km})$ \\
\hline Argentina & 977 & 957 \\
\hline Brasil & 1.537 & 1.537 \\
\hline Chile & 430 & 430 \\
\hline Paraguai & 559 & 318 \\
\hline Total & 3.503 & 3.242 \\
\hline
\end{tabular}

Fonte: adaptado de Parkinson (2020).

Em relação às obrigações firmadas pelas autoridades brasileiras, apenas a construção da ponte entre os municípios de Porto Murtinho (MS) e de Carmelo Peralta (AP), Paraguai, não está concluída. A empresa Itaipu Binacional ${ }^{11}$ criou um fundo

10 De acordo com a lei 6.634/79, é considerada área indispensável à Segurança Nacional a faixa interna de 150 quilômetros de largura, paralela à linha divisória terrestre do território nacional, que será designada como Faixa de Fronteira. Salvo com a anuência do Conselho de Defesa Nacional, é vedada a construção de pontes, estradas internacionais e campos de pouso, assim como transações com imóvel rural, que impliquem a obtenção, por estrangeiro, do domínio, da posse ou de qualquer direito real sobre o imóvel (Presidência da República, 1979).

11 A Itaipu Binacional foi constituída pelo tratado de Itaipu de 1973 para a operação da usina hidrelétrica homônima. Seu aspecto de empresa jurídica de direito privado binacional deve-se às ordens jurídicas de ambos os países às quais está submetida: Brasil e Paraguai (Itaipu, 2021). 
de US\$ 82 milhões para a construção dessa ponte, cuja licitação e supervisão das obras será de responsabilidade do Ministério de Obras Públicas y Comunicaciones do Paraguai. O prazo para a conclusão da ponte é de 2 anos (Mattos, 2021).

No Brasil, o estado do Mato Grosso do Sul (MS) tende a ser um dos mais beneficiados pela construção da RILA. A posição geográfica entre o estado brasileiro de São Paulo e o Paraguai proporciona ao MS a condição de elo logístico entre o maior PIB estadual do Brasil e um país vizinho que é um importante destino da produção nacional, devido, em parte, às dinâmicas comerciais mais densas derivadas do Mercosul (Mercado Comum do Sul). Além disso, MS destaca-se como grande produtor de commodities agrícolas e de carne bovina, o que influencia o padrão exportador desse estado, principalmente para a bacia do Pacífico e a América do Sul.

Em 2020, a corrente de comércio apresentada pelo MS corrobora a vinculação da produção estadual ao mercado externo. A maioria dos principais parceiros comerciais desse estado brasileiro poderão ser melhor acessados por meio tanto da RILA quanto por portos marítimos chilenos. Verifica-se na Tabela 2 que os fluxos comerciais desempenhados pelo estado do MS apresentam significativa vinculação intrarregional, principalmente com Bolívia, Chile, Argentina e Paraguai, e extrarregional, com China, Estados Unidos, Netherlands e Hong Kong. Entre esses países, apenas Netherlands não apresenta ganhos logísticos com a implantação da RILA.

Tabela 2. Corrente de comércio do Mato Grosso do Sul (2020)

\begin{tabular}{|l|c|}
\hline \multicolumn{1}{|c|}{ Pais } & Valor (em US\$ 1.000) \\
\hline $1^{\circ}$ China & 2.900 .000 \\
\hline $2^{\circ}$ Bolívia $^{12}$ & 991.000 \\
\hline $3^{\circ}$ Estados Unidos & 333.000 \\
\hline $4^{\circ}$ Chile & 243.000 \\
\hline $5^{\circ}$ Hong Kong & 220.000 \\
\hline $6^{\circ}$ Netherlands & 212.000 \\
\hline $7^{\circ}$ Argentina & 205.000 \\
\hline $8^{\circ}$ Paraguai & 172.000 \\
\hline
\end{tabular}

Fonte: adaptado de Comex Stat (2021).

A conclusão das obras da RILA, que está prevista para 2023, indica significativa redução de custos logísticos para mercadorias comercializadas no MS. Atualmente, a rota rodoviária que conecta esse estado aos portos chilenos apresenta extensão de 3.441 quilômetros. As cargas são transportadas por rodovias que cruzam a Argentina a partir da fronteira do estado do Rio Grande do Sul, no extremo sul do Brasil, o que aumenta substancialmente a distância percorrida e, por conseguinte, o custo de transporte. Além disso, a via marítima, por meio do porto de Santos, no estado de São Paulo, apresenta custos elevados, devido, principalmente, às operações portuárias, conforme apresentado na Tabela 3.

12 Em relação ao valor total de fluxos de comércio praticados com a Bolívia, em 2020, US\$ 962 milhões referemse à importação de gás natural realizada por segmentos produtivos brasileiros (Comex Stat, 2021). Esse insumo energético é transportado por meio do gasoduto Bolívia-Brasil, que passa pela superfície territorial de Mato Grosso do Sul e, por conseguinte, é registrado pelos serviços aduaneiros nesse estado. 
Tabela 3. Custos de transporte entre Campo Grande/MS (Brasil) e Antofagasta (Chile)

\begin{tabular}{|l|c|c|}
\hline \multicolumn{1}{|c|}{ Rota } & Extensão $(\mathrm{km})$ & Custo por tonelada (US\$) \\
\hline Porto de Santos - Canal do Panamá & 14.214 & 897,61 \\
\hline São Borja/RS - Argentina & 3.441 & 658,17 \\
\hline RILA & 2.254 & 433,81 \\
\hline
\end{tabular}

Fonte: adaptado de Parkinson (2020).

Além de cruzar quatro países, o que demanda harmonização aduaneira e de regras de transportes, a construção da RILA deve superar, também, o obstáculo das elevadas altitudes da cordilheira dos Andes. Nesse trecho, com altitudes que atingem mais de 3.000 metros, entre a província de Salta, na Argentina, e de Antofagasta, no Chile, há conexões rodoviárias e ferroviárias que passarão por modernização. Mesmo assim, a sinuosidade desses trechos dificulta a circulação de veículos de carga de grande porte, que são usados, predominante mente, no Brasil, para o transporte de produtos de menor valor agregado, como soja e milho. Assim, o trajeto da RILA apresenta, inicialmente, viabilidade econômica para produtos de maior valor agregado, que sejam transportados por meio de containers.

De acordo com a Tabela 4, é possível elencar celulose, carne bovina e farelo de soja como produtos oriundos do MS que apresentam maior potencial para serem escoados pela RILA e registrarem aumento de competitividade por mercados da América do Sul e bacia do Pacífico. Além desses produtos, a soja não transgênica, que apresenta maior valor de varejo e grande mercado consumidor na China, será economicamente viável, caso seja transportada por containers, pela RILA, visto que os baixos custos de operação portuária em Antofagasta compensarão o custo adicional de transporte rodoviário.

Tabela 4. Principais produtos exportados por Mato Grosso do Sul (2020)

\begin{tabular}{|l|c|}
\hline \multicolumn{1}{|c|}{ Produto } & Valor (em US\$ 1.000) \\
\hline $1^{\circ}$ Celulose & 1.700 .000 \\
\hline $2^{\circ}$ Soja & 1.620 .000 \\
\hline $3^{\circ}$ Carne bovina fresca, refrigerada ou congelada & 700.000 \\
\hline $4^{\circ}$ Farelo de soja e outros alimentos para animais & 332.000 \\
\hline $5^{\circ}$ Milho não moído & 326.000 \\
\hline
\end{tabular}

Fonte: adaptado de ComexStat (2021).

Em relação à carne bovina, as exportações brasileiras têm mantido a tendência de crescimento, à despeito da crise econômica global desencadeada pela pandemia de Covid-19. Essa tendência é fundamental para expandir a cadeia produtiva de carne bovina, principalmente no MS e no restante da região Centro-Oeste do Brasil, visto que concentram os maiores rebanhos do país. A cadeia produtiva de carne bovina abrange diferentes sistemas produtivos, fornecedores de serviços e insumos, indústrias de processamento e transformação, distribuição e comercialização de produtos e subprodutos, e seus respectivos consumidores finais. Em 2019, essa cadeia produtiva representou $8,5 \%$ do PIB do Brasil, com crescimento de $0,2 \%$ em relação ao ano anterior (Beef Report, 2020). 
Tabela 5. Maiores importadores de carne bovina produzida no Brasil (continentes/2020)

\begin{tabular}{|l|c|}
\hline \multicolumn{1}{|c|}{ Continente } & Valor (em US\$ 1.000) \\
\hline $1^{\circ}$ Ásia (exclusive Oriente Médio) & 4.000 .000 \\
\hline $2^{\circ}$ Oriente Médio & 604.000 \\
\hline $3^{\circ}$ Europa & 600.000 \\
\hline $4^{\circ}$ América do Sul & 516.000 \\
\hline $5^{\circ}$ América do Norte & 96.100 \\
\hline
\end{tabular}

Fonte: adaptado de Comex Stat (2021).

A importância econômica da cadeia produtiva de carne bovina para a economia brasileira justifica a busca de ampliação de mercados consumidores em outros países. Em 2020, a categoria carne bovina fresca, resfriada ou congelada atingiu o valor exportado de US\$ 7.446,88, o que representou um incremento de 13,8\% em relação ao ano anterior. Essa categoria representa 3,55\% das exportações brasileiras; ocupa o $5^{\circ}$ lugar no ranking de exportações nacionais e o $2^{\circ}$ lugar nas exportações da indústria de transformação (Comex Stat, 2021). Para Malafaia, Biscola y Dias (2020), a principal estratégica para ampliar o consumo de carne bovina produzida no Brasil é a obtenção de ganho de competitividade, por meio, por exemplo, da redução de custos de transportes.

Uma vez que os maiores mercados consumidores de carne bovina produzida no Brasil estão na Ásia, a conclusão da RILA torna um instrumento logístico fundamental à busca de redução de custos de transporte. De acordo com a Tabela 5, verificase que os mercados asiáticos são o destino de aproximadamente $70 \%$ das exportações brasileiras de carne bovina. Desse modo, os ganhos de competitividade derivados de maior eficiência logística tendem a ampliar a participação da produção brasileira nesses mercados, na ordem de 20\% (Parkinson, 2020).

Tabela 6. Transporte marítimo de cargas para Shanghai/China

\begin{tabular}{|l|l|c|l|}
\hline \multicolumn{2}{|l|}{ Rota } & Distância $(\mathrm{km})$ & Tempo de viagem \\
\hline \multirow{3}{*}{$\begin{array}{l}\text { Santos (Brasil) } \\
\text { e Shanghai } \\
\text { (China) }\end{array}$} & Via Canal de Suez & 25.078 & 56 dias e 10 horas \\
\cline { 2 - 4 } & Via Canal do Panamá & 24.156 & 54 dias e 8 horas \\
\cline { 2 - 4 } & Via Cape Horn & 22.143 & 49 dias e 20 horas \\
\cline { 2 - 4 } & Via Estreito de Magalhães & 21.989 & 49 dias e 11 horas \\
\hline \multicolumn{2}{|l|}{ Antofagasta (Chile) e Shanghai (China) } & 18.667 & 42 dias e 1 hora \\
\hline
\end{tabular}

Fonte: adaptado de Netpas Distance (2021).

Os ganhos de competitividade que serão proporcionados pela RILA derivam de diferentes variáveis. Embora a distância rodoviária entre Campo Grande/MS até os portos brasileiros de Santos e de Paranaguá seja inferior àquela entre Campo Grande/MS e Antofagasta, por meio do futuro trajeto da RILA, a distância marítima entre o litoral chileno e o porto de Shanghai, por exemplo, é significativamente menor, de acordo com a Tabela 6 . Desse modo, o transporte de cargas marítimas até a China é menor, o que determina, por conseguinte, menor custo de frete.

No entanto, a variável referente à redução de distância a ser percorrida e do tempo de viagem não deve ser a única a ser analisada quando se considera o custo total de frete internacional. Além da distância marítima menor, o porto de Antofagasta dispõe 
de outras vantagens em relação, por exemplo, ao porto brasileiro de Santos. O porto chileno apresenta custos de operações portuárias significativamente menores, do que aqueles do porto brasileiro, conforme evidenciado nos exemplos apresentados pelas Tabelas 7 e 8 .

Tabela 7. Custo médio de Praticagem portuária

\begin{tabular}{|l|c|}
\hline \multicolumn{1}{|c|}{ Porto } & Custo (US\$) \\
\hline Antofagasta (Chile) & $3.600 /$ navio \\
\hline Santos (Brasil) & $30.000 /$ navio \\
\hline
\end{tabular}

Fonte: adaptado de Parkinson (2020).

A praticagem é o serviço de assessoria aos comandantes de navios que trafegam em águas restritas, ou seja, onde há condições que dificultam a navegação livre, como portos e hidrovias (Minfra, 2016). No porto de Antofagasta, o custo de praticagem é aproximadamente $88 \%$ menor do que o praticado em Santos. Além disso, o custo de demurrage, que é a permanência de navio ou de contêiner nas dependências portuárias além do prazo estipulado em contrato, que é, geralmente, de 30 dias, é, também, significativamente menor no porto de Antofagasta. A tarifa de demurrage é cobrada por diária e cada transportador adota tabela própria. Em portos que a atividade de despacho aduaneiro não seja célere, é importante que essa tarifa seja menor possível, a fim de não onerar o custo total do frete (Campos, 2019). O custo médio de demurrage no porto de Antofagasta apresenta 50\% daquele cobrado no porto de Santos, o que reforça a competitividade das operações portuárias na instalação chilena.

Tabela 8. Custo médio de Demurrage

\begin{tabular}{|l|c|}
\hline \multicolumn{1}{|c|}{ Porto } & Custo (US\$) \\
\hline Antofagasta (Chile) & $15.000 /$ contêiner \\
\hline Santos (Brasil) & $30.000 /$ contêiner \\
\hline
\end{tabular}

Fonte: adaptado de Parkinson (2020).

A combinação entre redução de distância percorrida, de tempo de viagem e de custos portuários é suficiente para viabilizar o escoamento, por exemplo, de carne fresca, refrigerada e congelada por meio da RILA, embora a distância rodoviária entre Campo Grande/MS e o porto de Antofagasta seja maior do que aquela entre Campo Grande/MS e o porto de Santos, de acordo com a Tabela 9. Segundo Malafaia, Biscola y Dias (2020), os segmentos produtores de carne bovina projetam um aumento de produção na ordem de $23,8 \%$, sendo a carne bovina responsável pelo crescimento de $16,2 \%$, até 2030 . As mesmas projeções indicam, também, um elevado incremento das exportações de carne bovina brasileira, o que tornará o Brasil, em 2030, o líder na exportação desse segmento, com $28,7 \%$ do volume total mundial. Assim, a elevação da fatia de mercado da produção brasileira depende, inexoravelmente, de ganhos de competitividade, que, em parte, advirão da redução de custos logísticos. 
Tabela 9. Transporte marítimo de carne fresca, refrigerada ou congelada para Shanghai/China

\begin{tabular}{|l|c|l|c|c|}
\hline Rota terrestre & Extensão $(\mathrm{km})$ & Rota maritima & Extensão $(\mathrm{km})$ & $\begin{array}{l}\text { Custo (US\$) } \\
\text { por tonelada }\end{array}$ \\
\hline $\begin{array}{l}\text { Campo Grande - } \\
\text { Santos }\end{array}$ & 1.089 & $\begin{array}{l}\text { Santos - Canal } \\
\text { do Panamá - } \\
\text { Shanghai }\end{array}$ & 24.156 & 281,85 \\
\hline $\begin{array}{l}\text { Campo Grande - } \\
\text { Antofagasta }\end{array}$ & 3.441 & $\begin{array}{l}\text { Antofagasta - } \\
\text { Shanghai }\end{array}$ & 18.667 & 253,85 \\
\hline
\end{tabular}

Fonte: adaptado de Parkinson (2020).

Em relação a produtos importados que têm como destino os mercados consumidores de MS, conforme a tabela 10, adubos e fertilizantes químicos, que são oriundos, principalmente, da Rússia, do Marrocos e do Canadá (Comex Stat, 2021), e chegam ao Brasil por meio do porto de Santos, poderão ser fornecidos por empresas da costa oeste do EUA, com redução de aproximadamente $14 \%$ no custo de transporte, caso sejam desembarcados em Antofagasta e transportados pela RILA, até o MS (Parkinson, 2020). Na medida em que não somente o MS, mas, também, a região Centro-Oeste do Brasil, são grandes produtores agropecuários, essa redução proporcionará maior competitividade a esses segmentos nos mercados internacionais. Ademais, para que uma rodovia seja transformada em corredor econômico, é necessário, fundamentalmente, que fluxos de transporte de cargas ocorram nos dois sentidos, o que reforça a importância do transporte de produtos importados pelo Brasil por meio da RILA.

Tabela 10. Principais produtos importados pelo Mato Grosso do Sul (2020)

\begin{tabular}{|l|c|}
\hline \multicolumn{1}{|c|}{ Produto } & Valor (em US\$ 1.000) \\
\hline $1^{\circ}$ Gás natural, liquefeito ou não & 962.000 \\
\hline $2^{\circ}$ Adubos ou fertilizantes químicos & 292.000 \\
\hline $3^{\circ}$ Cobre & 122.000 \\
\hline $4^{\circ}$ Tecido, tramas, de matérias têxteis ou sintéticas & 64.700 \\
\hline $5^{\circ}$ Fios têxteis & 47.700 \\
\hline
\end{tabular}

Fonte: Comex Stat (2021).

Nesse contexto, os fluxos regionais de comércio tendem a se intensificar, na medida em que Argentina, Brasil Chile e Paraguai passem a transportar diretamente, por via rodoviária, bens e serviços comercializados regionalmente. Destarte, o cobre produzido e exportado por empresas sediadas no Chile, principalmente para o Brasil, ganha competitividade, no âmbito regional, ao passo que outros itens que não figuram, atualmente, entre as maiores importações realizadas pelo Brasil, como o trigo argentino, tendem a conquistar maior parcela do mercado do MS.

Destaca-se, também, a posição estratégica de Campo Grande/MS, no que se refere a acessos a importantes mercados consumidores regionais e nacionais do Brasil. Localizada no centro-sul do Brasil, o município de Campo Grande/MS está próximo de importantes aglomerados urbanos e industriais do estado de São Paulo; de áreas de grande produção agropecuária dos estados de Mato Grosso do Sul, do Mato Grosso, de Goiás e do Paraná; e de Brasília, capital do Brasil. Essa localização 
amplia a área de influência da RILA, uma vez que a capital do MS tende se tornar um centro de distribuição regional de cargas. A capilaridade rodoviária desse município é ampla e abrangente, o que potencializa os benefícios desse posicionamento estratégico, principalmente no que se refere a custos de transporte reduzidos. Brasília, a capital do Brasil, por exemplo, que está distante 1.005 quilômetros, apresenta um custo médio de transporte de carga de US\$ 211 por tonelada, enquanto Cuiabá, capital do estado do Mato Grosso, está distante 705 quilômetros e apresenta um custo médio aproximado de US\$ 150 por tonelada. Com base nessa posição estratégica e na fluidez logística resultante da construção da RILA, a prefeitura municipal de Campo Grande/MS concluiu a construção da infraestrutura do terminal intermodal de cargas, com previsão de movimentação de até 2.200 milhões de toneladas (CG Notícias, 2020).

Em suma, a construção da RILA resulta, em grande medida, da convergência de interesses de segmentos políticos e produtivos, em diferentes escalas. Enquanto na escala sul-americana, as autoridades nacionais têm buscado retomar o crescimento econômico por meio do incremento de exportações, na escala nacional e regional, agentes políticos fazem uso dessa conexão rodoviária como uma estratégia para promover o desenvolvimento e a integração regional, visto que o MS apresenta uma estrutura produtiva significativamente vinculada a mercados externos, além de ser um estado que dispõe de um posicionamento estratégico que lhe proporciona a condição de ser o elo entre o centro-sul do Brasil e os países vizinhos da América do Sul.

A sinergia entre os objetivos da escala internacional, da nacional e da regional resultou, também, na busca de dinamização na destinação de recursos para a conclusão das obras da RILA no território brasileiro, principalmente, a ponte internacional sobre o rio Paraguai, entre Porto Murtinho/MS e Carmelo Peralta/AP. Por meio da criação de um fundo, a Itaipu Binacional destinou aproximadamente US\$ 82 milhões para a realização dessa obra, o que se confirmou em um processo mais célere do que os procedimentos orçamentários governamentais.

Essa busca de desenvolvimento regional com base na estrutura produtiva atual angariou o apoio de segmentos produtivos e de entidades setoriais vinculadas a essa estrutura. Identificou-se, por meio de pesquisa realizada em diferentes segmentos políticos e produtivos, que entidades relacionadas ao segmento de logística, como a Federação das Empresas de Transporte Rodoviário de Passageiros dos Estados de Mato Grosso e o Sindicato das Empresas de Transporte de Cargas e Logística de Mato Grosso do Sul, e de carnes bovinas, como a Associação Brasileira das Indústrias Exportadoras de Carnes, interpretam a construção da RILA como um instrumento essencial para alavancar a economia regional por meio da intensificação de exportações $^{13}$.

Para a Associação dos Produtores de Soja e Milho de Mato Grosso, a implantação da RILA tende a ampliar os fluxos comerciais regionais e internacionais. Há um potencial de complementariedade produtiva que não dispõe de infraestrutura logística para ser atingido. Entretanto, devido às características altimétricas da cordilheira

13 Informações obtidas por meio da realização de pesquisa de campo, realizada por meio de aplicação de questionário aberto para representantes de entidades setoriais, com base em questões acerca das potencialidades logísticas da RILA para o respectivo segmento produtivo representando. A aplicação desses questionários ocorreu em março de 2021. 
dos Andes e às limitações de circulação de caminhões de grande porte na Argentina e no Paraguai, o escoamento de soja não seria, inicialmente, viável. O transporte de soja não transgênica, que é demandada por mercados asiáticos, poderá ocorrer por meio da RILA, desde seja realizado por meio de containers, malgrado a elevação do custo final do produto. Para a Confederação Nacional da Agricultura (CNA), a RILA será uma alternativa logística importante para a exportação da soja produzida no centro-sul do Brasil. A prioridade, contudo, para essa entidade, é a conclusão, principalmente por parte do governo brasileiro, de redes de infraestrutura de transportes que dinamizem as exportações nas regiões Norte e Nordeste do país, visto que apresentam vias rodoviárias, ferroviárias e hidroviárias escassas em relação à crescente produção de grãos que ocorre nessas regiões.

\section{Novos usos territoriais em Porto Murtinho, MS, Brasil}

Grande parte do contingente populacional e dos segmentos produtivos brasileiros estão próximos à fachada atlântica, devido a um processo histórico desigual de ocupação. Essa formação socioespacial deriva, também, da divisão territorial do trabalho, cuja manifestação é a hierarquização entre os lugares e a redefinição da capacidade de agir das pessoas, das firmas e das instituições (Santos e Silveira, 2003, p.20). Como resultado desse processo, regiões que apresentam vínculos mais intensos com mercados globais dispõem de maior concentração de sistemas de engenharia, técnicos, de capital humano e financeiro, ao passo que as demais regiões são caracterizadas por baixas densidades de capital, populacionais, técnicas e informacionais, com restrita fluidez nas circulações, o que caracteriza, nessas regiões periféricas, a existência de "espaços opacos" (Santos, 1999, p.194).

A construção da RILA visa, principalmente, à maior competitividade de exportações oriundas de uma estrutura produtiva existente, principalmente, em MS, baseada na agropecuária. Essa tendência, contudo, não impede que essa infraestrutura rodoviária não estimule o desenvolvimento de áreas que, atualmente, não sejam consideradas economicamente dinâmicas. Com base nessa possibilidade, o município de Porto Murtinho surge como potencial entroncamento multimodal na fronteira entre Brasil e Paraguai.

Porto Murtinho é um município que integra o estado do Mato Grosso do Sul. Situado na Microrregião do Baixo Pantanal, o núcleo urbano do município está localizado na latitude $21^{\circ} 41^{\prime} 56^{\prime \prime}$ Sul e na longitude 57 $52^{\prime} 57^{\prime \prime}$ Oeste. Está distante 437 quilômetros de Campo Grande, capital do MS, e 1.463 quilômetros de Brasília, capital do Brasil (IBGE, 2021). Por estar assentado na margem esquerda do rio Paraguai, Porto Murtinho dispõe de conexão hidroviária à montante, com o Pantanal SulMato-Grossense, embora a navegação seja inviável durante a estação sem chuvas, e à jusante, com o Paraguai, e com os Departamentos argentinos de Chaco, Corrientes, Entre Ríos, Santa Fé e Buenos Aires (Porto Murtinho, 2020).

Na margem direita do rio Paraguai, no Departamento de Alto Paraguay, está situado o município de Carmelo Peralta. Embora as infraestruturas de transportes 
disponíveis sejam precárias, há fluxos transfronteiriços entre Carmelo Peralta ${ }^{14} \mathrm{e}$ Porto Murtinho ${ }^{15}$. Atualmente, esses fluxos apresentam características capilares, uma vez que as interações ocorrem somente no nível local, como a realização de feiras. Além disso, a ocorrência de trocas difusas entre os habitantes desses municípios vizinhos constrói um padrão de integração espontânea (MI, 2005).

A conclusão das obras da RILA, notadamente da ponte binacional, entre Porto Murtinho e Carmelo Peralta mudará significativamente o padrão de integração fronteiriça. Prejudicado pela distância em relação à capital do MS, Campo Grande, que concentra grande parte das atividades industriais e de serviços do estado, e em relação aos principais centros econômicos do Brasil, Porto Murtinho também sofre restrições, no que se refere à atração de investimentos estrangeiros, devido à localização na área de Faixa de Fronteira do Brasil. No entanto, a posição estratégica do município favorece a superação desses obstáculos econômicos e legais.

A dificuldade de navegação à montante do rio Paraguai durante o período de ausência de chuvas, entre março e setembro, tem inviabilizado o uso de portos fluviais nessa área, uma vez que o calado do rio Paraguai se torna muito raso. Desse modo, após a conclusão a implantação de infraestrutura rodoviária até o porto fluvial, por meio do PROEXP (Programa de Estímulo à Exportação ou à Importação pelos Portos do Rio Paraguai), o governo do MS tem estimulado o uso e a construção de terminais para armazenagem de grãos, como um modo de ampliar os investimentos em Porto Murtinho e, ao mesmo tempo, evitar que a produção de grãos do estado perda competitividade, devido à dificuldades logísticas e aos elevados custos de embarque apresentados pelos portos de Santos e de Paranaguá (Andrade, 2021).

A soja escoada pelo porto do município de Porto Murtinho/MS tem como destino os portos de San Lorenzo e Timbues, na província argentina de Santa Fé. Nessa província, a soja é transformada em farelo e em óleo e, posteriormente, exportada. Com contratos de exportação de 500.000 toneladas desse grão, as autoridades portuárias de Porto Murtinho/MS registraram o incremento de 57,83\% no volume registrado de exportações, com base no ano de 2019 (Andrade, 2021). Para Parkinson (2020), a conclusão da RILA proporcionará que o beneficiamento dessa matéria-prima, que agrega valor ao produto final, seja realizado no município de Porto Murtinho/MS e, depois, exportado. Destarte, esse município passará a desempenhar importante papel na cadeia regional de beneficiamento da soja, uma vez que, por meio da RILA, ampliará as exportações de derivados de maior valor agregado.

A construção de novos terminais portuários e as obras rodoviárias, decorrentes tanto do melhoramento dos acessos portuários quanto da adaptação de trechos da rodovia BR 267, que liga Porto Murtinho a Campo Grande, a capital do estado do Mato Grosso do Sul, tem ampliado a oferta de empregos e, por conseguinte, a renda média local. Nesse contexto, de acordo com Chaves (2020), as autoridades estaduais projetam transformar esse município fronteiriço em um $h u b$ logístico internacional. Essa projeção, contudo, tem enfrentado limitações socioeconômicas relacionadas à

14 Carmelo Peralta é um município que integra o Departamento do Alto Paraguay (AP). Está distante aproximadamente 730 quilômetros de Assunção, capital do Paraguai, e apresenta uma população de 4.000 habitantes (MTIC, 2020).

15 A população estimada de Porto Murtinho é de 17.298 habitantes. Apenas 8,1\% da população está formalmente ocupada. Aproximadamente 40,4\% apresenta rendimento médio igual ou inferior a $1 \frac{2}{2}$ salário mínimo (US\$ 194, com base na cotação de 1 US\$ = R \$ 5,67). Além disso, aproximadamente $80 \%$ das rendas do município são oriundas de fontes externas (IBGE, 2021). 
falta de ordenamento territorial, à escassez de mão de obra qualificada e a influência restrita das autoridades municipais acerca do modo como ocorrerá a construção da RILA em Porto Murtinho.

Assim como grande parte dos municípios brasileiros, Porto Murtinho não dispõe de instrumentos de ordenamento territorial. O crescimento urbano espontâneo, na margem esquerda do rio Paraguai, em uma planície de inundação, tornou a cidade vulnerável a enchentes recorrentes. A construção de um dique fluvial em torno da cidade, em meados da década de 1980, protegeu a cidade de inundações, mas limitou a expansão do sítio urbano aos limites desse dique. Na medida em que a construção da RILA iniciou, começou a ocorrer intensa demanda imobiliária, devido ao potencial de investimentos a serem destinados ao município de Porto Murtinho, o que resultou em rápida valorização de imóveis locais:

Uma parte da população local tem se animado a vender seus imóveis diante da valorização e passam a enfrentar um outro problema: a ausência de ofertas de imóveis para venda, devido à escassez e também à elevação dos preços, dessa forma àqueles que vendem os próprios imóveis, resta a possibilidade de buscar áreas mais distantes, além dos limites do dique fluvial, para construir casas, muitas vezes de formas improvisadas. Isso também acontece com as famílias que chegam de outras regiões de MS, a fim de buscar melhores oportunidades de vida (Antônio José Ângelo Motti) ${ }^{16}$.

$\mathrm{O}$ resultado é o surgimento de aglomerados subnormais em áreas propensas à inundação, o que tem pressionado o governo municipal a buscar soluções. A principal delas surge do apoio do MDR (Ministério do Desenvolvimento Regional), que aportou recursos para financiar a participação de especialistas de instituições de Ensino Superior de MS. Esses especialistas constituíram um GT para apoiar o município de Porto Murtinho na construção de um Plano Diretor Municipal, que proporcione não somente o atendimento das demandas locais por crescimento econômico e social, por meio de melhor ordenação do sítio urbano, mas, também, a identificação de possibilidades de verticalização predial, em função do predomínio da existência de solos argilosos e arenosos, que são típicos de planícies inundáveis. Desse modo, esse GT busca identificar as condições ideais para o desenvolvimento local para os próximos dez anos.

A disponibilidade de mão de obra qualificada é outro desafio a ser enfrentado pela sociedade de Porto Murtinho. A maior parte da população adulta dispõe de apenas o ensino fundamental completo. (IBGE, 2021) Embora haja crescente demanda de mão de obra pouco qualificada, como o embarque e o desembarque de cargas e a construção civil, as projeções de ampliação do fluxo de caminhões, de embarcações fluviais, de armazenagem de grãos e, por conseguinte, de pessoas, demandará trabalhadores aptos a realizar atividades relacionadas à manutenção automotiva, naval, de infraestruturas de armazéns; atividades hoteleiras; bancárias; de saúde; de alimentação, entre outras. O Centro de Triagem Mécari, que é um terminal apto a receber até 400 caminhões, conta com serviços de hotel, restaurante e centro comercial. Entrou

16 Dados de entrevista realizada com o pesquisador Antônio José Ângelo Motti, que tem realizado estudos e levantamentos de dados de Porto Murtinho para concluir o Plano Diretor Municipal. Entrevista realiza em 25 de março de 2021. 
em operação em 2020, mas enfrenta dificuldades para contratar trabalhadores para os serviços disponibilizados (Semagro, 2021). Embora o governo estadual tenha estabelecido um convênio com o Sistema $\mathrm{S}^{17}$ e com a prefeitura de Porto Murtinho, ainda não houve a identificação de perfis profissionais que serão futuramente demandados.

A construção da RILA tem o potencial de transformar o município de Porto Murtinho em um centro logístico internacional. Os investimentos públicos e privados que têm sido destinados ao município indicam que a RILA é, verdadeiramente, um instrumento de desenvolvimento local e regional. Paulatinamente, as intervenções federais e estaduais têm adaptado a infraestrutura urbana de Porto Murtinho a um contexto de maior afluxo de pessoas e de veículos de carga e de passeio. No entanto, as limitações econômicas, sociais e políticas que grassam o poder decisório da escala local tendem a dificultar a inclusão a população local nesse processo que pode criar um novo paradigma de integração fronteiriça na América do Sul.

\section{Considerações finais}

A construção da RILA, que será concluída até 2023, apresenta potencial para impulsionar os fluxos de bens e de pessoas entre Argentina, Brasil, Chile e Paraguai. Além de exportações mais competitivas para mercados da bacia do Pacífico, por meio de portos chilenos, os segmentos produtivos desses países apresentam possibilidade de complementariedade comercial no âmbito regional. Em uma conjuntura de retração dos fluxos internacionais de comércio, como desdobramento da pandemia Covid-19, a recuperação das economias sul-americanas passa pela integração de infraestruturas logísticas.

Na medida em que a ampliação da participação em cadeias regionais e globais de valor representa incremento de poder, autoridades governamentais e representantes de segmentos produtivos atuam, na escala sul-americana, na nacional e na estadual, por meio de diferentes modos, a fim de dinamizar a construção da RILA e de obter ganhos setoriais de competitividade. Nesse contexto, representantes públicos e privados, que atuam na escala local, no município de Porto Murtinho, Mato Grosso do Sul, Brasil, também buscam projetar interesses em relação à RILA. No entanto, devido à assimetria de poder, esses representantes não conseguem exercer a mesma influência que é praticada por atores de outras escalas. Embora Porto Murtinho tenha recebido importantes investimentos públicos e privados nos últimos anos, problemas estruturais, como limitação de espaço para expansão urbana, especulação imobiliária e escassos meios para qualificar mão de obra, permanecem como grandes desafios para as autoridades, embora comecem a ser enfrentados pelo conjunto das instituições, por meio, por exemplo, de iniciativas vinculadas ao Sistema S.

$\mathrm{O}$ crescimento econômico de regiões transfronteiriças é um instrumento estratégico que garante a segurança do território nacional. As dinâmicas produtivas decorrentes RILA podem forjar um paradigma de integração baseado em um amplo

17 O Sistema S é um conjunto de instituições prestadoras de serviços que são administradas de forma independente por federações e confederações empresariais dos principais setores da economia brasileira. Mantidas com recursos das empresas de cada setor produtivo, essas organizações oferecem um conjunto variado de serviços à população, como escolas, cursos técnicos, pesquisas, atividades culturais e esportivas (Lisboa, 2020). 
espectro de prosperidade social e política, desde que o objetivo principal não apenas levar desenvolvimento às pessoas, mas, acima de tudo, prover o desenvolvimento das pessoas.

\section{Agradecimentos}

O autor agradece os comentários e as sugestões de Gloria Vargas Lopez de Mesa, José Drummond e Gustavo Baptista, além da disponibilidade para compartilhar conhecimentos e experiências por meio de entrevistas do ministro José Carlos Parkinson, de Dorival de Oliveira, Edeon Vaz, Carlos Silva, Antônio José Ângelo Motti e Elisângela Pereira Lopes.

\section{Referências bibliográficas}

Andrade, S. (2021). Investimentos do Estado em logística em Murtinho avançam fronteira agrí́cola no Sudoeste. Portal do Governo do Estado do Mato Grosso do Sul. Disponível em http://www.ms.gov.br/investimentos-do-estado-em-logistica-em-murtinho-avancamfronteira-agricola-no-sudoeste/

Antaq. (2019). Metodologia de Gestão de Riscos e Integridade de 2019. Agência Nacional de Transportes Aquaviários. Disponível em https://www.gov.br/antaq/pt-br/assuntos/gestao-estrategica/gestao-de-riscos-e-integridade/METODOLOGIA_ANTAQ_VERSAO_18_02_20.pdf

Batista, E. (1997). Infraestrutura para desenvolvimento sustentado e integração da América do Sul. São Paulo, Brasil: Editora Expressão e Cultura.

Beef Report. (2020). Perfil da Agropecuária do Brasil 2020. Associação Brasileira das Indústrias Exportadoras de Carnes. Disponível em https://www.cicarne.com.br/wp-content/uploads/2020/05/SUMÁRIO-BEEF-REPORT-2020_NET.pdf

Bitencourt, J. (2021). Este dia na história: início da Guerra do Pacífico - $1^{\circ}$ de março de 1879. Revista Relações Exteriores. Disponível em https://relacoesexteriores.com.br/guerra-dopacifico/

Campos, A. (2019). Demurrage: entenda sobre a sobreestadia de container. AC Campos Importação e Exportação Ltda. Disponível em http://accamposcomex.com/blog/demurrage-entenda-a-sobreestadia-de-container/

CEPAL. (2021). Perspectivas del Comercio Internacional de América Latina y el Caribe, 2020. Santiago, Chile: Comisión Económica para América Latina y el Caribe.

Cepalstat. (2021) Bases de Datos y Publicaciones Estadísticas. Comisión Económica para América Latina y el Caribe. Disponível em https://estadisticas.cepal.org/cepalstat/Portada.html

Chaves, B. (2020). Promessa de hub logístico, Porto Murtinho recebe investimentos públicos, privados e internacionais. Governo do Estado do Mato Grosso do Sul, Brasil. Disponível em http://www.ms.gov.br/nao-liberar-ainda-promessa-de-hub-logistico-porto-murtinhorecebe-investimentos-publicos-privados-e-internacionais/

CG Notícias. (2020). Prefeitura conclui obra do terminal multimodal de Campo Grande. Agência Municipal de Notícias de Campo Grande, MS, Brasil. Disponível em http://www.campogrande.ms.gov.br/cgnoticias/noticias/prefeitura-conclui-obra-do-terminal-intermodal-de-campo-grande/ 
Cosiplan. (2020). Ejes de Integración y Desarrollo. Consejo Suramericano de Infraestructura y Planeamiento. Disponível em http://iirsa.org/Page/Detail?menuItemId=68\&menuIte$\mathrm{mId}=135$

Cosiplan. (2017). Cartera de Proyectos 2017. Quito: Foro Técnico IIRSA. Comité de Coordinación Técnica del Consejo Suramericano de Infraestructura y Planeamiento (COSIPLAN). Disponível em http://www.iirsa.org/Document?menuItemId=5

Comex Stat. (2021). Portal para acesso às estatísticas de comércio exterior do Brasil. Comex Stat. Disponível em http://comexstat.mdic.gov.br/pt/home

Efe. (2017). Macri propone que China colabore con IIRSA para conectar Asia con Sudamérica. Agência EFE. Disponível em https://www.efe.com/efe/america/economia/macripropone-que-china-colabore-con-iirsa-para-conectar-asia-sudamerica/200000113266462

Faria, J. H. (2003). Poder e relações de poder nas organizações. Em M. Vieira e C. Carvalho (eds.), Organizações, instituições e poder no Brasil (pp. 68-120). Rio de Janeiro, Brasil: FGV.

Gama, A. (2018). Escalas, representações e ação social. Cadernos de Geografia, (17), 17-21.

Herrera, D. S. (2019). Geopolítica de la fragmentación y poder infraestructural. El Proyecto One Belt, One Road y América Latina. Geopolitica(s). Revista de estudios sobre espacio y poder, 10(1), 41-68.

IBGE (Instituto Brasileiro de Geografia e Estatística). (2020). Porto Murtinho. IBGE Cidades. Disponível em https://cidades.ibge.gov.br/brasil/ms/porto-murtinho/panorama

Itaipu. (2021). Perfil Institucional da Itaipu Binacional. Itaipu. Disponível em https://www.itaipu.gov.br/institucional/gestao-transparente

Lisboa, V. (2020). O que é o Sistema S? Agência Brasil/EBC. Disponível em https://agenciabrasil.ebc.com.br/economia/noticia/2020-09/agencia-brasil-explica-o-que-e-o-sistema$\mathrm{s}$

Machado, L. O. (1998). Limites, fronteiras, redes. Em T. Strohaecker, A. Damiani, N. Schaffer, V. Dutra (orgs.), Fronteiras e Espaço Global (pp. 41-49). Porto Alegre, Brasil: Associação dos Geógrafos Brasileiros.

Malafaia, G. C.; Biscola, P. H. N., e Dias, F. R. T. (2021). Projeções para o Mercado de Carne Bovina do Brasil - 2029/2030. Boletim CiCarne. Disponível em https://www.embrapa.br/documents/1355108/51748908/BoletimCiCarne020.pdf/df10a41a-b09a-d460$2455-4717 \mathrm{~b} 738 \mathrm{a} 03 \mathrm{c}$

Mattos, A. (2021). Lançada licitação para construção de ponte entre MS e Paraguai. Midiamax. Disponível em https://www.midiamax.com.br/politica/transparencia/2021/lancadalicitacao-para-construcao-de-ponte-entre-ms-e-paraguai

MI (Ministério da Integração Nacional). (2005). Programa de Desenvolvimento da Faixa de Fronteira: proposta de Reestruturação do Programa de Desenvolvimento da Faixa de Fronteira. Brasília, Brasil: Secretaria de Programas Regionais. Ministério da Integração Nacional.

Minfra (Ministério da Infraestrutura (2016). Praticagem. Gov.br Governo Federal. Disponível em https://www.gov.br/infraestrutura/pt-br/assuntos/transporte-aquaviario/praticagem

MOPC (Ministerio de Obras Públicas y Comunicaciones). (2020). Gobierno obtiene financiamiento para el tramo 3 de la Ruta Bioceánica. Ministério de Obras Públicas y Comunicaciones. Disponível em https://www.mopc.gov.py/index.php/noticias/gobierno-obtienefinanciamiento-para-el-tramo-3-de-la-ruta-bioceanica 
Moraes, A. C R. (2005). Ordenamento territorial: uma conceituação para o estratégico. In: Para pensar uma Política Nacional de Ordenamento Territorial (pp. 43-47). Brasília, Brasil: Ministério da Integração Nacional. Disponível em https://www.mdr.gov.br/images/stories/ArquivosSNPU/Biblioteca/publicacoes/ordenamento_territorial.pdf

MRE (Ministério das Relações Exteriores). (2019). Surgimento do PROSUL. Gov.br Governo Federal. Disponível em http://www.itamaraty.gov.br/pt-BR/politica-externa/integracao-regional/20939-surgimento-do-prosul

MRE (Ministério das Relações Exteriores). (2015). Declaração de Assunção sobre Corredores Bioceânicos. Gov.br Governo Federal.Disponível em https:/www.gov.br/mre/pt$\mathrm{br} /$ canais_atendimento/imprensa/notas-a-imprensa/atos-adotados-por-ocasiao-da-li-reuniao-do-cmc-e-da-li-cupula-de-chefes-de-estado-do-mercosul-e-estados-associados-brasilia-20-e-21-de-dezembro-de-2017\#III

MTIC (Ministerio de Tecnologías de la Información y Comunicación). (2020). Municipalidad de Carmelo Peralta. Ministerio de Tecnologías de la Información y Comunicación. Disponível em https://www.municipios.gov.py/carmeloperalta/\#

Netpas Distance. (2021). Distance Table. Netpas.net. Disponível em https:/www.netpas.net/products/detail/nd

Página 12. (2021). Catamarca logró instalar la Comisión del Corredor Bioceánico em el FOVIRA. Página 12. Disponível em https://www.pagina12.com.ar/329984-catamarca-logro-instalar-la-comision-del-corredor-bioceanico

Parkinson, J. C. (2020). Rota Bioceânica: conheça os detalhes do corredor (Palestra). Portal $V G V$. Disponível em https://www.youtube.com/watch? $\mathrm{v}=$ crz6sxotHn $8 \& \mathrm{t}=4075 \mathrm{~s}$

Porto Murtinho. (2021). Indicadores. Prefeitura Municipal de Porto Murtinho, MS, Brasil. Disponível em http://www.portomurtinho.ms.gov.br/indicadores/2/extensao-territorial

Presidência da República (1979). Lei no 6.634. Presidência da República, Casa Civil, Subchefia para Assuntos Jurídicos. Disponível em http://www.planalto.gov.br/ccivil_03/LEIS/L6634.htm

Raffestin, C. (1993). Por uma Geografia do Poder. São Paulo, Brasil: Ática.

Santos, M. (2000). Por uma outra globalização: do pensamento único à consciência universal. Rio de Janeiro, Brasil: Record.

Santos, M.. (1999). A natureza do espaço: espaço e tempo: razão e emoção (3. ed.). São Paulo, Brasil: Hucitec.

Santos, M., e Silveira, M. (2003). O Brasil: território e sociedade no início do século XXI (5. ed.). Rio de Janeiro, Brasil: Record.

Semagro (Secretaria de Estado de Meio Ambiente, Desenvolvimento, Produção e Agricultura Familiar). (2021). Governo entrega acesso ao Terminal logístico de Porto Murtinho que vai controlar fluxo de veículos aos portos. Semagro, Mato Grosso do Sul, Brasil. Disponível em https://www.semagro.ms.gov.br/governo-do-estado-investe-no-acesso-ao-terminal-logistico-de-porto-murtinho-que-controlara-fluxo-de-veiculos-aos-portos/

Wegner, R. (2018). Integração e desenvolvimento econômico: estratégias de financiamento do investimento de infraestrutura sul-americana. Economia e Sociedade (Campinas), 27(3), 909-938. Disponível em https://www.scielo.br/pdf/ecos/v27n3/1982-3533-ecos27-03-0909.pdf 